\title{
Modes of University Government
}

\author{
W. M. SIBLEY*
}

\section{"University Government" - Three Modes or Periods}

University administrative officers and members of the legal profession are nowadays being brought into relationships over a whole range of matters which in less complex and more tranquil times were of little or no joint concern. In an earlier age, universities could and did exist in a state of considerable detachment from and ignorance of many aspects and points of law. That former state of ignorance is rapidly being reduced by ever more frequent consultations with our solicitors, and by growing involvement with arbitration panels, courts, and regulatory bodies of one kind or another. Some of these bodies, it would appear, are having as much difficulty in fathoming the peculiar nature of a university as are academics in discerning their particular modes of ratiocination and operation. If anything is clear, it is that we are certainly going to become better acquainted with one another: universities with the law and law with the universities. Any dialogue which has as its aim the fostering of better understanding of the problems now becoming matters of joint and urgent concern, and of the immediate or potential import of an emerging series of judicial rulings pertinent to the management of university affairs, will be of increasing value and even necessity.

But how do universities "manage their affairs"? What do we mean when we speak, rather vaguely, of "university government"? The term itself is not one I am particularly comfortable with, even though it has been in common use for ten years or more. Like many other new coinages, its appearance and quick adoption into ordinary parlance signified, if in an obscure and confused way, some profound changes which were beginning to overtake the university; it pointed to incipient disputes about its nature, its constitution, and its role in the contemporary world. What in effect was being signified was the dissolution of an older and unchallenged order of things; and the importation of new models or analogies (in this case, the political) in terms of which to cope with what was happening. This dissolution of older reality has proceeded apace, and with increasing velocity, over the last decade. One of its chief consequences has been the inability of the university to contain and resolve within itself a number of conflicts, some now of major proportions. No society can endure without adequate conflict resolution mechanisms. It is this very failure of conflict resolution mechanisms which brings us into the courts and before labour relations boards, and therefore into contact at many points with the legal profession. In so far as the term "university government" is supposed to connote the existence of a community capable of managing its own affairs, it is to a significant

*Vice-President (Academic), Mount Allison University. 
degree already outmoded. Nevertheless, before it disappears (as I believe it will) it can at least serve as a springboard for some comments about what has been going on within our institutions and some speculations about what may lie ahead.

What has been happening within the university? and why do the worlds of the university and the law now intersect over much wider regions than was formerly the case? To answer this question I shall provide an account of three major phases, or periods, or "ages" through which "university government" has moved, corresponding to three distinct modes of management of our internal affairs. I must acknowledge that in this account I shall be speaking from my own experience and perspectives: I know of no way in which to excise the personal or what some would call the "subjective" element. One's own experience and attitudes inevitably enter into one's appreciation of the very nature of a situation, as well as into one's stance regarding what is to be done. (Getting "an agreed statement of facts" before an arbitration board, as many of us know, is often as difficult as resolving the dispute itself.) Nor do I claim to be describing the condition of every institution: I am thinking in particular of the context within which large, complex, highly differentiated universities now function and of the stresses and deformations they have undergone in the past ten to fifteen years. Here and there some relics of a previous and more tranquil age may survive: if so, long may they endure. What is tolerably clear is that many of our institutions are no longer in such happy case, or we should not be represented here today.

For my part, I spent over twenty-five years, as a student, staff member, department head, and then faculty dean in several universities which functioned throughout that time in a mode which one could fairly characterize as belonging to the Age of Authority - the first of the three periods I wish to discuss. One might equally describe it as an age of legitimacy; as a period in which (barring the odd and remarkable court case) conflicts were contained and resolved within a well-ordered, though not explicitly defined, structure or constitution. Towards the end of the 1950's and the early 1960's, we began to move, at first gently but then with greater velocity, into a quite distinct period. This was the Age of Participation: the age of the Duff-Berdahl report, which both encapsulated and stimulated trends towards the creation of quite different types of faculty, senate and board structures. One began to hear the term, "university government"; one began to hear of some new entity styled "the administration"; one heard talk of the "legislative" and "executive" branches of the university; and academics elected to senate came to be designated not as "members of Senate" but by the august and portentous word, "Senators". During this era, we moved rapidly away from a condition in which nearly everything was done by custom and convention, with few or no elaborate rules of order, codes of tenure and discipline, and so forth, into a positive frenzy of legislation. Still, it was legislation by the university community and for its own affairs; in the main, no external bodies were involved, except in so far as it was necessary to petition legislatures for changes in university acts.

Towards the end of the 1960's, this new mode of conducting our affairs seemed well entrenched. Within a remarkably short space of time, however, some of our institutions moved from this second period into a third and much more troubled age, one of the most notable characteristics of which is that conflict has escalated to the point where frequently it can no longer be resolved within our institutions but is being carried for adjudication 
and disposition to external agencies, such as courts and regulatory boards. What to call this present stage I do not quite know. It is clearly an age of litigation; it is an age of dissent; it is an age of dissolution of the valence bonds which formerly held a university together in genuine community. It is an age of marked incoherence: on the one hand, academics still speak of a "community of scholars" and then proceed, divided into two (or more) camps, to appear before some labour relations board, whose role essentially is to organize the fight. The contradiction appears obvious. It is an age in which adversary relationships are displacing collegial relationships; and in which "university government" is becoming thoroughly unstuck. Caught in perplexity as to what to call it, I shall simply term it the Adversary Age, and let it go at that.

\section{The Age of Authority}

I shall not dwell overlong on an account of the first phase - the one I have styled the Age of Authority. As compared with later periods, I think it fair to say that it was an era of marked stability and tranquillity. The sense of belonging to a distinctive community, different not only from other types of organizations but different in traditions and collective memory even from other universities, was strong, indeed almost palpable. The principle of seniority was dominant: young men (as I can vividly recall) were expected even (as I was) formally instructed, that for the first few years their role was to be seen, not heard. Conflict, of course, was not unknown. Every university had its share of fiercely combative, eccentric professors, not at all chary of engaging in cut-and-thrust argument of a highly polemical nature at faculty or senate meetings. Aside from the occasional and celebrated case, however, conflict was nearly always contained and resolved within the fabric of the institution; and the university's structure of authority tended not to suffer direct or serious challenge. To the best of my recollection, no one then spoke of "the university administration" except in reference to such non-academic functionaries as the registrar and the bursar. The department head, the dean, and the even more remote figure of the principal or president were simply "the authorities", and were indeed typically so referred to in the press. Their power to direct and shape the course of the institution invariably took into account academic influences; but it was nonetheless dominant. Indeed, in an age when both within and without the university there seem to be so many destroyers, so many "un-makers", it is salutary to recall that the word "authority" is derived from the Latin words auctor and auctoritas, both of which stem from the verb augeo: to cause to grow or increase. In that now remote age, the authorities were, for better or for worse, the custodians and exemplars of the university's traditions; the arbiters of its conflicts; and the moulders and makers of its future.

No society is perfect, and of course this ancient mode - now light-years removed was not without its share of mistakes and injustices. Not surprisingly, and especially as (during the 1950's) the economic condition of the staff worsened, local staff associations began to develop and organize themselves so as to make more effective representations to the president and the then all-powerful boards of governors. As a founding member of one such staff association, and quondam front rank activitist, I can well recall some of these early meetings. Nothing, by the way, so incensed us during these sessions with our Board - one could hardly call them "confrontations" - - as the assertion or imputation by Board members that we were merely "employees" of the institution. If there 
then was one thing which professors stoutly resisted, it was the application of such a term with all that it conveyed and all that it correspondingly repudiated and threatened in what we saw (and I think rightly) as the unique nature of the university and the role of the staff who, as we liked to say, were the university. That academics would one day insists on being classed and treated as "employees" and would appear before labour relations boards we could not possibly have envisaged: we felt in our bones that we were members of an ancient guild, even though we could not well deny that our livelihood was provided by the state. We could have said (with the philosopher Butler) that the university is what it is, and not another thing. What is more, we would have been right.

\section{The Age of Participation}

Towards the close of the 1950's, universities began to slip their moorings and to move - at first gently but then with increasing velocity - into a quite different period. As we all know, the decade of the 1960's was a time of tremendous growth and change in our colleges and universities. New institutions were created by the dozen: older ones were changed out of all recognition, both in scale and in complexity, in size and in differentiation and specialization of functions. The ancient boundaries between the university and society began to break down, with consequences only now becoming apparent. For those of us who were engaged in acquiring the necessary facilities and in recruiting and retaining staff, it was a time of great strain, but nonetheless one of considerable euphoria. Many problems are - for a while - greatly eased by the prospects of growth. (As a dean I used to tell my then president that I had no problems which another million dollars wouldn't cure.) We were on a flood tide; and if through some navigational error we got ourselves stranded, we knew that the rising waters would soon float us free. Entering a tricky harbour on an ebb tide, of course, is a quite different matter, demanding navigational skills of the highest order. That discovery, however, was to be left to our successors in the 1970's.

Accompanying these expansions in physical plant and numbers, in increased differentiation and affluence, there was a marked movement towards greater participation by both staff and students in what was by then universally coming to be called "the governance of the university". In general, faculty and to some degree students gained much greater numerical representation on academic senates; and in many institutions even on boards of governors. The powers or functions of academic senates were often vastly enlarged, to include access to financial data hitherto reserved for boards of governors, and to influence markedly, indeed, practically to determine, decisions on budgetary as well as academic matters. Not only was it an age of increased participation; it was also (as I have noted) an age of legislation: of the creation of elaborate tenure codes, dismissal codes, grievance procedures, disciplinary procedures, rules of order for the conduct of meetings, as well as a host of regulations on other items: all of them displacing the rudimentary body of legislation on which, in conjunction with custom or convention, our affairs had formerly rested.

Hardly had these changes been fully effected, however, in the latter part of the 1960's, than signs of disappointment and then trouble began to appear. We slipped from a period of euphoria into one of increasing malaise. ${ }^{1}$ The grand experiment in democratic governance was turning out not to please anybody to the extent that had been hoped. "The 
administrators", now openly spoken of as "civil servants" (yet another false analogy) came to be held "accountable" for committee decisions over which they had ceased to have any real control and to which they might even have expressed opposition. Students came to feel themselves threatened, especially by movements towards unionization amongst the academic and non-academic staffs. Though they had gained some kind of representation at the highest levels, they began to feel that they had merely been "coopted", and had become in some ways more powerless than before. In this conviction they were not entirely wrong. Junior faculty, although in fact they had the power to combine at election time to secure a voice for their concerns on senate and board, began to complain that university affairs were still too much in the hands of their seniors. Governments became alarmed at our soaring expenditures. About 1970, the word "accountability" suddenly became fashionable: an old word indeed, but now coming to be used in a new and diffused sense, and expressing, even if loosely and vaguely, the uneasy sense that affairs were slipping out of control, both within and without the university.

In moments of confidentiality, some university presidents have recently been heard ' to say that their large, complex, highly differentiated institutions have become almost "ungovernable." Power seems to have been dispersed everywhere, and is therefore effectively nowhere. Motion in any direction seems to encounter drag or resistance, or to suffer from various forms of blockage or distortion. Our systems have come to be characterized by what I have elsewhere termed high impedance - one of the salient features of which is that struggles to overcome problems frequently end in making them more intractable. ${ }^{2}$ As all of these strains increase, and as the boundaries between universities and the external complex of social, political and economic forces are eroded, certain conflicts arise which can no longer be resolved or even contained within the fabric of the institution. In consequence, aggrieved individuals or associations are seeking recourse before arbitration boards, before courts, and before regulatory boards. The "Adversary Age" is here. Hence the encounter of universities with the law, and law with the universities; and the urgent need for a joint exploration of our common concerns.

\section{The Adversary Age - A Third Level of Conflict}

In characterizing these three periods of the evolution of university government, I have had of necessity to advert frequently to the theme of conflict and its resolution and containment. In the first period, conflicts were in the main localized, and readily muted or contained, without basic challenge or threat to the system and to authority. At the second stage, where the rules themselves were under attack and change was demanded, authority inevitably became involved, but left its lofty perch to engage on one side or the other of the struggle. For example, when (during the late 1960's) universities everywhere engaged in the complex task of revision of their various university acts, altering their structures in the direction of a much more participatory mode, members of governing boards typically went along with the change, some with real misgivings but for the most part in a constructive and co-operative spirit. The order itself was changed; but the principle of ordering remained intact. What Vickers has termed "the constraints and assurances of membership", namely, our sense of our mutual obligations to one another, and our overriding concern that even in a dispute nothing should be done to imperil 
future relationships between the parties, was still strong; and was for some time adequate to preserve the valence bonds and hence the integrity and unity of our institutions. ${ }^{3}$ Latterly, however, this old sense of collegiality has become much weaker, and adversary relationships more marked. In consequence, conflict tends to escalate to a third level, in which the position of authority itself is challenged. At this stage, conflict takes place not within the rules, and not merely about the rules, but over the power to change the rules.

I do not mean to imply that the old bonding has quite vanished - else universities would be mere aggregates of individuals, with no recognizable identity whatever. Old habits and traditions of course still exist, but they do so in increasingly uneasy juxtaposition with such new trends as collective bargaining, in which the former power of a governing board to make unilateral decisions affecting the staff has been removed by instrumentalities of the law itself. When this point is reached, it is clear that the institution's own conflict resolution mechanisms are breaking down. The fundamental meaning of such a change - the dissolution of community - is plain.

\section{The University As An "Organized Anarchy"}

If the golden days of the Age of Participation are turning out to have been shortlived, if "participation" has turned out to be a fragile mode of operation, the causes are not to be attributed wholly to the idea of participation itself. To be sure, during the 1960 's much nonsense got talked; there was a great deal of ferment without much form; but some of the changes introduced were beneficial and long overdue. These changes, however, occurred in the context of a number of other circumstances which, taken together, have affected both universities (and indeed other complex organizations) in such a way as to make central control and management increasingly difficult. That is a note now being sounded frequently in the analyses of leading authorities in the field of organization theory. ${ }^{4}$ Looking at universities in particular, for example, writers such as March and Cohen, in Leadership and Ambiguity, have characterized them as "organized anarchies" - in which it is sometimes a wonder that decisions get made at all. ${ }^{\mathbf{5}}$

What, in brief, are some of these forces? which, in my view, show no signs of abating and some of which may even wax greater? For one thing, the markedly increased differentiation of the modern university raises problems. Differentiation in itself bring with it seeds of disagreement and conflict. In proportion as it increases, so does the need for closer and more intensive integration. A working consensus becomes more difficult of achievement. Yet the achievement not merely of verbal but of real consensus and hence of integration depends upon a level of genuine communication. Communication, however, is thwarted by a second change: namely, the enormous increase in size or scale of many institutions. As scientists from Aristotle down to the present have known, it is simply not possible, either in the physical world, or in the biological or social, to increase (or decrease) the size of a system while "keeping everything else the same." In our mad rush towards expansion not only did we ignore the implications inherent in the laws of scaling: we also changed at a pace which was in itself too extreme. Altogether, the mutation was too great and too sudden. It destroyed much of our collective memory of what a university was. As Sir Eric Ashby has noted, it is the experience of a biologist that large mutations are invariably lethal. There is no reason to think that educational, business or governmental enterprises are immune from such effects. 
Still other forces have been at work upon us. Participation in decision-making has become far more fluid, as short term appointments became the vogue and as so many affairs got referred to committees of constantly changing composition. (I think such changes were not necessarily inherent in the idea of participation itself, but rather in some quite erroneous notions about "democratizing the university", i.e., of introducing a political process and tone into what is not and cannot be a political affair.) Instability and discontinuity thereby came to characterize our processes of decision. Accountability came unstuck, as responsibility and authority became separated. In the last two to three years, the numbers of participants have greatly increased, as government departments or their agencies have come to play a larger role in our affairs. What is especially alarming in this regard is that so many of these functionaries are anonymous or hidden: tucked away in the layers of governmental bureaucracy, they affect decisions by what, in their discretion and frequently ignorance, they choose to ask for in the way of information and by what, again in their discretion, they choose to transmit or to filter out. It would seem that sometimes they are accountable really to no one: not even to the ministers to whom, in formal theory, they are supposed to be responsible.

I cannot give a complete catalogue of these newly operating factors, but I must mention one final instance: the disappearance of "slack" in our system. Financial retrenchment is now the vogue and inflation is taking its alarming toll of our resources. When an organization loses its slack or reserve, conciliation and compromise become more and more difficult of attainment. The "net energy load" - the relationship between the demands made on the system and its capacity to respond - rises sharply, and decision-making correspondingly shows down.

As March and Cohen argue, in three fundamental respects universities, as organizations, differ from a business or industrial enterprise of a conventional kind. In the first place, their basic objectives or goals are fundamentally unclear and problematic. They cannot readily be operationalized so as to give clear directives for forward motion: a fact which we often cover up by the device Braybrooke and Lindblom call "the naive priorities" method. 6 That is, we make grandiloquent but toothless statements about our objectives which are altogether lacking in operational bite. Secondly, our technology is imperfect: we do not really have a handle on measuring our "input" or "output" and therefore on assessing our efficiency and effectiveness. At best, we are forced to use indirect or proxy measures. We operate large and complex "management information systems", which, however, often tend to produce more "data" than really useful "information." Thirdly, there occurs the problem (already noted) of fluid and transient participation in decision-making.

In consequence of these characteristics, the decision-making style within many large institutions (especially in times of crisis) is usually not one of direct attack on a problem, or of what March and Cohen call "resolution". Decisions are frequently made by "flight", as when contentious issues or concerns gravitate to some other arena of choice. Or they are made by "oversight": out of desperation or accident somebody somewhere does something, and the critical precedent is established. As I have earlier observed, all of these difficulties are becoming accentuated by the increase in the number of participants in decisions; by the growing influence of anonymous bureaucrats; and by the disappearance of slack or reserve capacity in our resources. In consequence, universities 
are becoming decisional paraplegics, more and more forced to turn to external agencies or to governments for answers to their problems. Caught as we are in a vortex of economic, social and political forces, I think it highly probable, then, that our encounters with the law will mutiply, at any rate over the next few years, which promise to be very troubled times indeed.

\section{Conclusion}

It is not difficult to foresee many of the problems we shall be entangled with. We shall (for example) be concerned about problems having to do with the legal status of student unions; or about faculty and student rights in disciplinary proceedings; about grievances over denial of tenure, or withholding of merit increments and promotions; about the application of admission quotas; and perhaps above all with the institution and operation of collective bargaining contracts. Depending upon the context, many subsidiary issues will arise. For instance, in what sense are university staff on "contracts"? I have heard spirited discussions on this point - which, however, seem to unearth more problems than answers. If staff are on contracts, is anyone really able to say with confidence what "full time service at the university" means? If I am on sabbatical leave, am I or am I not on such service? Or again: where does my tenure as a professor lie? With the department, in the context of which one is examined for tenure, or with the university? If the latter, what are the implications if financial pinch turns to financial crunch and terminations become necessary? What is the status of "confidential" documents (e.g., tenure appraisal forms) as used by many universities? In this last connection, I have read with great interest, though not yet with full comprehension, the very recent judgment of the Supreme Court in the case of Slavutych $v$. the Board of Governors of the University of Alberta, which (I believe) has immediate pertinence in many related contexts. Or finally: what is going to happen if, as seems quite probable, a given university act in some respects conflicts with a provincial labour relations act?

As to our involvement with regulatory boards, I am inclined to believe that, willynilly, their actions will somewhat resemble those of Procrustes, who fitted his guests to the available bed rather than vice-versa. The statutes and practices of labour relation boards, for instance, have not been designed with such peculiar entities as universities in mind, so that such boards in rendering decisions are not equipped with precise surgical instruments for carving along the natural joints. In the resulting operation, the patient can get severely mangled. If he arrived merely in a state of trauma, he may leave as a basket case, to be cured only by court or eventually by governmental action.

As to what will occur in our courts, I would speculate that as critical issues come before them, the essential problem must surely be to determine under what precedents and therefore analogies a given case should be brought. I do not think this task will be simple. For one thing, many of our practices and procedures developed in a context and on certain assumptions which are ceasing to be operative. How does one relate the effects of a vanished past to the realities of the present? Moreover, notwithstanding the changes they have undergone, universities are still such intricate entities that one might safely predict the occurrence of rulings which, as in the Slavutych case, will be chal- 
lenged all the way up to the Supreme Court. Precisely what a decision of that body may mean in another particular case may raise still further problems. In general, I would suppose that we shall all be in a state of considerable confusion and uncertainty for some years to come. One hopes that eventually we will settle down into a more stable condition, arrived at because of the pragmatically induced need for mutual accommodation if we are to get on with our essential business - which is what does go on and must continue to go on in our lecture halls, libraries and laboratories. Much of our old institutional autonomy will have vanished; but I am confident that if we are resolute enough in its defense, most of what is truly valuable in what may properly be termed "academic freedom" will survive. Governments (one hopes) will find that universities are quite intractable beasts to manage in any detail; and that academics are remarkably ingenious in finding ways to thwart undue intervention into the inmost essence of their scholarly affairs.

In the meantime, it is at any rate imperative to open and to sustain civilized and rational dialogue between the universities and the law. Failure to achieve such dialogue would seriously imperil the very survival of universities as we have known them, and of the contributions which, whatever their shortcomings, they alone are qualified to render to society.

\section{Notes}

1 By 1971-72, the malaise was becoming an object of frequent comment. See, for example, the 1972 study by B. I. Adell and D. D. Carter, Collective Bargaining for University Faculty in Canada. (Industrial Relations Centre, Queen's University, Kingston, 1972).

2 Sibley, W. M. "The Transactional Frame of Accountability." In Evaluating Institutions for Accountability (ed. H. R. Bowen). San Francisco: Jossey-Bass, 1974.

3 Vickers, G. "The Management of Conflict." Futures, 19724 (2), pp. 126-141.

4 See, for instance, the very penetrating analysis by G. T. Allison, in Essence of Decision. (Boston: Little, Brown, 1971).

5 Cohen, M. D. and March, J. G. Leadership and Ambiguity. Carnegie Foundation for the Advancement of Teaching. McGraw Hill: 1974. (References are chiefly to Chapter 5: The Processes of Choice, pp. 81-91.)

6 Braybrooke, D. and Lindblom, C. E. Strategy of Decision. New York: The Free Press, 1970, pp. 6-8. 